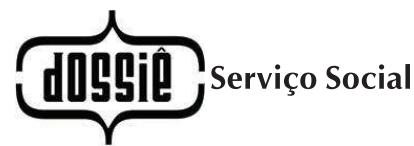

Militantes do Movimento de Oposição Metalúrgica/SP, de movimentos sociais, da igreja e parlamentares durante o cortejo do operário Santo Dias da Silva, assassinado por policiais durante piquete na greve dos metalúrgicos de São Paulo, em 30 de outubro de 1979. Acervo do Intercâmbio, Informações, Estudos e Pesquisas (IIEP). Fundo: Oposição Sindical Metalúrgica de São Paulo (OSMSP).

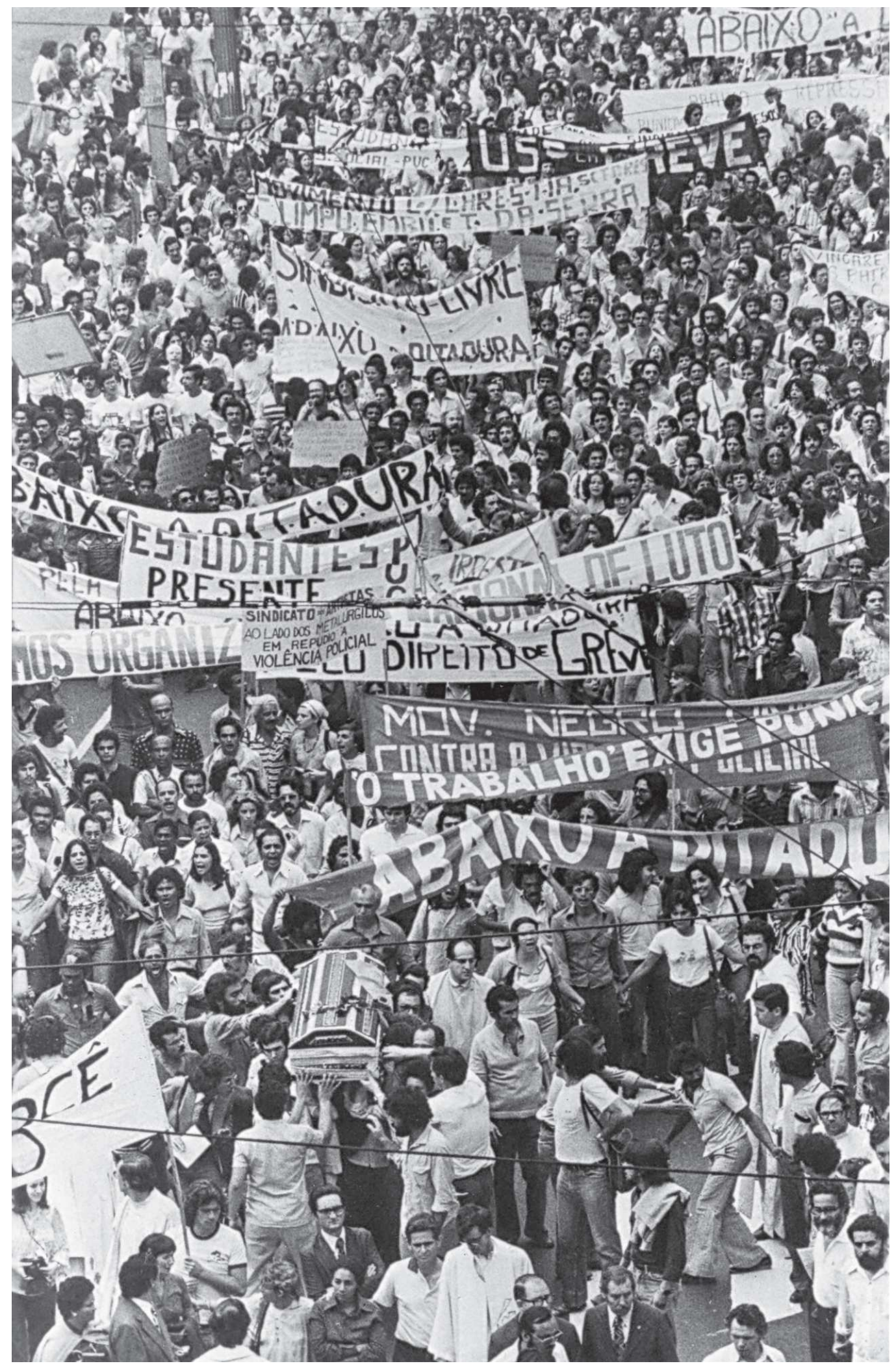




\title{
A Assistência Social no Universo da Proteção Social - Brasil, França e Argentina
}

\author{
Silvina Maria Carro*
}

\begin{abstract}
Resumo: Este trabalho analisa a assistência social nos sistemas de proteção social do Brasil, da França e da Argentina, privilegiando dois cortes: a passagem das formas assistenciais do campo privado para o campo público e sua relação com a seguridade social. O texto oferece indicações sobre as tensões que contribuem para melhor delinear o lugar da assistência social na passagem das formas privadas às públicas.

Palavras-chave: Proteção social; assistência social; seguridade social; direitos sociais.

Abstract: The article analyzes social assistance within Social systems protection framework following its movement from public to private services areas. The author search for its relations to broader social security systems focusing on centralization/decentralization processes as the main organizational and political changes at 1980 decade.

Keywords: Social protection; social assistance; social security; social rights.
\end{abstract}

Esse artigo apresenta estudo sobre a configuração da assistência social nos sistemas de proteção social do Brasil, da França e da Argentina, ocupando-se da passagem das formas assistenciais do campo privado para o campo público e sua relação com a seguridade social ${ }^{1}$.

Introduzo essa exposição lembrando que no ano de 2001, a Organização Internacional do Trabalho (OIT), durante a Conferência Internacional do Trabalho, lançou a Campanha Mundial sobre Segurança Social e Cobertura para Todos ${ }^{2}$. A estimativa do organismo previa que, a cada cinco pessoas no mundo, apenas uma

\footnotetext{
* Doutora e Mestre em Serviço Social pelo Programa de Pós-Graduação em Serviço Social da Pontifícia Universidade Católica de São Paulo (PUC-SP). Endereço postal: Av. Higienópolis, 870, São Paulo, CEP: 01238000. Endereço eletrônico: silvinacarro@gmail.com

1 Agradeço à Professora Doutora Aldaíza Sposati por suas orientações metodológicas, de leitura, e pelas oportunidades dadas no processo de orientação da pesquisa de tese de doutoramento, parcialmente apresentada neste artigo. Expresso meu agradecimento ao conjunto dos professores do Programa de Pós-Graduação em Serviço Social da PUC-SP, por sua receptividade, generosidade e sabedoria. À Coordenação de Aperfeiçoamento de Pessoal de Nível Superior (Capes), ao Conselho Nacional de Desenvolvimento Científico e Tecnológico (CNPQ), pelo inestimável apoio econômico ofertado por meio da bolsa de estudos que permitiu a realização do curso de doutorado e mestrado.

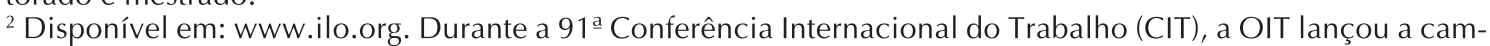
panha mundial sobre Seguridade Social e Cobertura para Todos, apresentada oficialmente por Juan Somavia, o então diretor-geral da OIT.
} 
delas teria uma cobertura de segurança social adequada. As outras quatro pessoas teriam igualmente necessidade desta cobertura, embora vivessem sem ela de alguma maneira.

No documento então elaborado, a OIT define segurança social como a proteção oferecida por uma sociedade às pessoas e famílias, destinada a garantir o acesso à assistência sanitária e à seguridade, particularmente em situações de idade avançada, desemprego, doença, deficiência, lesão profissional, maternidade ou perda do suporte familiar. O documento acrescentou dados que indicavam que $80 \%$ da população mundial carecia de um nível adequado de cobertura de seguridade social, isto é, mais da metade dos habitantes do planeta não disporiam de nenhum tipo de proteção. Os governos e as organizações de empregadores e de trabalhadores consideraram que deveria ser dada máxima prioridade às políticas e iniciativas de segurança social para todos aqueles que não possuem cobertura nos sistemas existentes.

A ausência de proteção social extensiva a todos os que dela necessitam é um problema legítimo que merece ser considerado. A constatação do fórum da OIT exprime que as metas formuladas em meados do século $X X$, e que foram a base da institucionalização dos sistemas de proteção social nas sociedades ocidentais, estão longe de ser alcançadas.

No andamento das sociedades modernas, a assistência social, como parte desses sistemas de proteção social, contribuiu com os movimentos de ampliação de seus conteúdos e suas proteções, assim como com os movimentos de retração da sua presença no sistema, quando a seguridade social foi considerada como já plenamente estendida. Nas últimas décadas, a inserção ou não inserção da assistência social nas sociedades com alto nível de desemprego, de migração externa e interna, e desigualdade social, tem colocado o foco nas chamadas políticas de inserção ou de inclusão social e dos programas de transferência de renda. Contudo, a falta da abrangência social da proteção no mundo continua sendo um problema a ser resolvido no século XXI.

A análise da assistência social e da forma que ela toma no conjunto da proteção social de cada país, seja em sua formulação baseada em direitos, seja nos planos e políticas e em sua forma de institucionalização, constitui um dos caminhos possíveis para consolidá-la como campo de política pública e de acesso aos direitos. Ao mesmo tempo essa abordagem da questão permite confrontar diversas definições produzidas em outros campos da academia, assim como coopera na produção de um tipo de conhecimento que melhora a ação pública nessa área.

Os projetos, programas e serviços sociais, sustentados numa definição de assistência social como política de direitos, têm fundamental importância para o enfrentamento da desigualdade social naqueles países que possuem um sistema de proteção social ainda não desenvolvido ou em desenvolvimento e, consequentemente, para o estudo sobre como estender a proteção para o conjunto dos seus habitantes.

Essa perspectiva contribui para a análise da configuração da assistência social nos sistemas de proteção social de diferentes formações históricas: no Brasil, na França e na Argentina, enquadrados na realidade histórico-social e política de cada 
um desses países. Assim como facilita problematizar o processo de continuidade e descontinuidade das regulações desses sistemas a partir de dois cortes: a passagem das formas socioassistenciais do campo privado para o campo público, e a assistência social em sua relação com os sistemas de seguridade social, na perspectiva de aprofundar como essa inclusão pode ter sido qualificadora ou não qualificadora da assistência social quando vinculada ao conjunto de prestações fornecidas pela proteção social .

O estudo buscou preservar a singularidade de cada país na análise do tema, sem uniformizar a coleta de dados, nem forçar a existência das mesmas variáveis para conhecer o fenômeno. Não se pretendeu transpor modelos de um país para outro. Sua importância esteve no conhecimento das diversas experiências, com seus trajetos próprios de interrogações e de imprevistos, como algo já realizado e avaliado por outros sujeitos sociais ou por novas gerações, de modo a reconhecer antecipadamente naquele contexto, naquela conjuntura, a natureza dos problemas e as suas possíveis soluções. Seguindo a proposta de Hugo Zemelman ${ }^{4}$, em relação aos estudos comparados de políticas públicas, não há aqui o propósito de "provar" um conceito, mas, sim, de descobrir sua especificidade no interior de uma articulação.

Para avaliar a assistência social, tanto no momento da inclusão de direitos sociais nas cartas constitucionais, na centralização e introdução de técnicas na política de assistência social, como no momento da extensão dos seguros sociais, foi utilizado um critério descritivo que faz referência a sua natureza funcional e à área de problemas à qual se destina. Cada Estado processou isso de maneira diferente, revelando tendências e movimentos específicos ${ }^{5}$.

\footnotetext{
${ }^{3}$ A escolha desse tema decorreu, em primeiro lugar, das indagações surgidas a partir do estudo das produções acadêmicas sobre o direito à assistência social no Brasil, incorporado como tal na Constituição brasileira de 1988, assim como de outros estudos relativos ao tema desenvolvidos no Núcleo de Estudos e Pesquisa sobre Assistência Social e Seguridade Social (Nepsas), e nas disciplinas do Programa de Pós-Graduação em Serviço Social da PUC-SP. Essas produções me colocaram em face do desafio de pensar e "me pensar" na situação de meu país de origem: Argentina, e de como poderia descrever, e fazer refletir sobre aquela realidade, a trajetória de desenvolvimento da assistência social no conjunto da proteção social, além de me levar a retomar os estudos já realizados por outros colegas argentinos nessa perspectiva. Esse processo ampliou-se, quase simultaneamente, para a realidade francesa, sendo então estimulada por minha orientadora a incluir essa dimensão na pesquisa proposta pelo Projeto Capes-Cofecub, "A Proteção Social contra a Exclusão Social e a Serviço da Inclusão Social". Nesse projeto, participaram docentes e estudantes da França e do Brasil. Estiveram envolvidas a Pós-Graduação em Serviço Social da PUC-SP e a Equipe de Pesquisas Econômicas e Sociais (ERES) da Faculdade de Economia e Gestão da Université Pierre Mendès France de Grenoble. O trabalho foi coordenado pela Professora Doutora Aldaíza Sposati, pelo lado brasileiro, e, do lado francês, pelo Professor Doutor Alain Euzeby. Um dos objetivos deste estudo foi desenvolver trabalhos de pesquisa, nos dois países, para analisar as políticas voltadas à inclusão social de assistência social, transferência de renda, assistência social voltada às crianças e adolescentes, e ações dirigidas ao atendimento de urgências no plantão social.

${ }^{4}$ Nora KRAWCZYK, Reginaldo MORAES, Estudos comparados, projeto histórico e análise de políticas públicas: entrevista com Hugo Zemelman, 2003. Nessa entrevista o Professor Zemelman, aborda os problemas metodológicos nas análises políticas que trabalham com a noção de comparação e sua preocupação em propor o desafio da construção de um conhecimento sobre a realidade latino-americana que incorpore a historicidade dos diferentes processos nacionais, isto é, a complexidade dos fenômenos políticos, sociais, culturais ou econômicos no momento em que eles são abordados.

${ }^{5}$ Reconhece-se que o Estado estabeleceu, e ainda estabelece, relações constitutivas de associação ou parceria com organizações sociais privadas ligadas a práticas assistenciais. A prática da assistência social não fica restrita aos organismos públicos de prestação direta de serviços. Subvenções ou convênios são repassados às entidades sociais privadas, assim como a execução de programas socioassistenciais e de serviços de infraestrutura social (creches, asilos, centros de formação de mão de obra, centros de reabilitação). Nesse sentido, foram examinadas somente aquelas formas que, por sua magnitude e presença pública, poderiam colaborar para a compreensão das discussões e desafios contemporâneos da política de assistência social.
} 
A França é o país que conta com informação mais sistematizada e organizada em relação à proteção social, e à política de assistência social como parte de um sistema. O Brasil conta com um número importante de contribuições produzidas pela academia, e pelos organismos de governo. No caso da Argentina, a análise apresentou-se mais complexa, pois não existe tradição de estudo da assistência social como um direito social; há contribuiçõos que tenderam a propor esse debate a partir do Serviço Social ${ }^{6}$; há uma tradição de estudo sobre a seguridade social ancorada no campo do Direito, e estudos financiados por organismos internacionais, como a OIT, que descrevem a proteção social na Argentina a partir da década de 1990.

A escolha da proteção social como enquadramento para estudar a assistência social na evolução dos três países decorreu do caráter amplo que o conceito tem em relação a outros enquadramentos, pela própria definição jurídico-administrativa, e pela possibilidade de incorporar processos de institucionalização de programas e serviços, em três conformações sócio-históricas e políticas diferentes. Na França, a assistência social não faz parte do que se considera a seguridade social, no sentido da definição clássica do termo, mas tem longa tradição como parte da proteção social e como parte do direito administrativo. No Brasil, a assistência social faz parte da seguridade social, desde a sua inclusão na Constituição Federal de 1988. $\mathrm{Na}$ Argentina, a assistência social é possível de ser estudada a partir dos processos de institucionalização de categorias e benefícios.

Quanto ao legado de dispositivos e programas de proteção social e sua articulação, a Argentina registrou importante desenvolvimento no início do século XX, com a introdução e expansão de instituições e programas de corte bismarkiano, ligados a um contexto de pleno emprego. Paralelamente, desenvolveram-se políticas públicas que colaboraram na expansão e provisão de bens públicos. A complexidade do estudo é dada pela estrutura federativa das instituições públicas e provoca permanente fragmentação das propostas de proteção. Embora tenha havido momentos nos quais convergiram propostas de unificação e estandardização de programas, a separação de responsabilidades e funções entre os diferentes níveis do governo (nacional e provincial) pode ser um dos obstáculos para o estudo da assistência social, entre outras proteções.

O exame da realidade de cada país partiu de uma rota similar orientada pelas categorias que embasam essa reflexão, considerando sempre as distintas variáveis que moldam a trajetória sócio-histórica de cada país analisado. Nesse emaranhado de particularidades é possível identificar, na análise das Constituições; dos processos de institucionalização da assistência social; da relação desta com a extensão do seguro social e dos processos recentes de descentralização políticoadministrativa, o início de um percurso estritamente restrito à ordem jurídica positiva: Constituição, leis, regulamentos, enquanto base legal. Ainda assim, o recurso ao

\footnotetext{
${ }^{6}$ Debates já registrados, como o do Professor Norberto Alayón, em seu trabalho Assistência ou assistencialismo, e algumas pesquisas recentes, como a iniciada pelas Professoras Gloria Mendicoa e Claudia Krmpotic, nas quais se discutem as dimensões da institucionalização do social no Mercosul.
} 
exame das Constituições nacionais não configura um enfoque legalista para este estudo, mas à inclusão dessa dimensão às demais aqui examinadas para cada país.

$\mathrm{O}$ segundo roteiro adotado nesse caminho investigativo buscou colocar a assistência social em situação de análise, isto é, procura identificar fontes não somente por meio do estudo de textos ou da jurisprudência, mas sim dos registros que permitem examinar os processos de sua institucionalização e as alterações que a ela apontam em tempos posteriores. Portanto, para essa abordagem, a proposta foi a de caracterizar a inserção da assistência social na arquitetura do sistema de proteção social, com ênfase na passagem das primeiras formas de assistência social às primeiras formas reguladas e o seu enquadramento jurídico-administrativo.

$\mathrm{O}$ terceiro roteiro destacou os fundamentos do direito à assistência social, priorizando sua expansão e alcance no estudo das constituições, ementários ou leis fundadoras, assim como das disposições administrativas que poderiam dar conta da sua explicitação.

A periodização da análise não foi predeterminada; ela foi registrada para cada país a partir do momento em que a seguridade social coexistiu com a assistência social, buscando identificar os princípios reitores, os domínios e as articulações entre ambas, se existiram, com ênfase na delimitação das prestações oferecidas, das categorias de usuários aos quais se orientou a assistência social, e as condições de admissão.

\section{A Configuração da Assistência Social}

No devir dos Estados modernos, a interpretação do trabalho como o eixo organizador da vida dos cidadãos ergueu-se ao lado de outras concepções que diferenciavam aqueles que recebiam dinheiro ou ajuda sem o correspondente esforço esperado para ganhá-los. Nesse enfoque, a assistência social apareceu como residual e definida como necessária quando não houve eficiência em outras políticas voltadas à regulação trabalhista. Contudo, parafraseando o Professor Vicente de Paula Faleiros (1989) "a organização da assistência social sempre foi um problema para a sociedade capitalista", e, em particular, para a arquitetura institucional do Estado moderno.

Embora a etapa mais intensa de preocupação estatal com a proteção social dos seus cidadãos, em face das necessidades advindas das vicissitudes da vida em sociedade, tenha ocorrido do fim do século XIX ao século XX, durante os séculos $\mathrm{XVI}$ e XVII, aconteceram importantes regulações, que acompanharam o processo de secularização da vida social e política dos Estados modernos.

$\mathrm{Na}$ França, durante o período monárquico, foi oficializada uma das primeiras instituições de assistência no século XVI, o Grande Ofício dos Pobres de Paris, mas sob o objetivo da defesa social. Com a Declaração dos Direitos do Homem e do Cidadão, em 1789, é que se extinguiram os privilégios feudais e foi determinada uma dívida social da sociedade para com aqueles cidadãos em situação de necessidade e a prescrição de mecanismos de proteção consubstanciados nos socorros públicos como expressão da solidariedade social. Ainda assim, o processo de regulação foi se construindo entre os vestígios de sentimentos religiosos ou humanistas.

A Poor Law, promulgada em 19 de dezembro de 1601, foi considerada um ponto de partida para o processo de reconhecimento da necessidade de atendimento 
daqueles que sofriam os efeitos do incipiente processo de industrialização. Essa lei assentou-se em quatro princípios: a) a obrigação do socorro aos necessitados; b) a assistência pelo trabalho; c) a taxa cobrada para o socorro aos pobres; d) a responsabilidade das paróquias pela assistência de socorros e de trabalho.

O Estado desempenhou um papel crucial na construção da identidade nacional francesa, e uma das suas finalidades foi integrar as diversas partes do país. Em meados do século XIX, um quarto da população não falava o francês e morava em comunas com idiomas próprios. A maioria dos franceses vivia na zona rural, afastada dos grandes centros. Nessa época, era comum referir-se à existência de uma França civilizada, culta, herdeira da revolução e do espírito iluminista, e, outra, que exprimia o espírito do Antigo Regime de características conservadoras, próprias das comunas afastadas da capital.

O processo de impor coesão a uma sociedade tradicionalmente dividida, teve início durante o Antigo Regime e avançou por toda a Revolução Francesa e o período napoleônico. A Terceira República estendeu-se por setenta anos e seus maiores desafios ancoraram-se nas tensões existentes entre Paris e as províncias; a influência das comunas e as identidades locais; a relação entre Estado e Igreja e as revoltas sociais associadas à industrialização. Nesse contexto, as ciências sociais emergiram como instrumento das reformas políticas.

A legislação nacional francesa para a área da assistência social pública que se ergueu nesse período ancorou-se nesses objetivos de unificação nacional e colocou definitivamente o Estado na posição de órgão prestador de assistência àqueles que - por idade, saúde e deficiência congênita ou adquirida - não tiveram meios de garantir sua própria subsistência. Desde o século XV, já se vinham perfilando as categorias de beneficiários e o território, mas foi durante a III República Francesa que se definiram o ordenamento das primeiras leis de assistência social pública e a institucionalização de um Conselho Superior de Assistência Pública. Do mesmo modo que foram regulamentadas no nível nacional as condições do direito e da pertença comunal como eixos da prática assistencial, assim como a existência de uma administração de assistência para cada comuna (HATZFELD, 1971; CASTEL, 1997; THÉVENET, 2004).

A Argentina encontrou, na Constituição de 1853, uma fórmula que deu conta das diferenças de interesses entre as elites regionais, mas a unidade efetiva do território só viria a se concretizar em $1862^{7}$. Mesmo depois disso, até 1880, o novo governo central careceria não apenas de uma capital, mas de uma instituição financeira e da faculdade de emitir moeda. A Argentina não dispunha de uma administração nacional, de funcionários, de práticas administrativas, nem sequer de edifícios públicos que o simbolizassem. A Constituição argentina de 1853, reformada em 1860, permaneceu inalterada durante quase um século (FAUSTO e DEVOTO, 2004. p. 93-100).

A Sociedade de Beneficência de Buenos Aires foi criada antes desse período de unificação nacional, em 1823, e se conformou como uma das formas de inter-

\footnotetext{
${ }_{7}^{7}$ A Constituição de 1853 foi aceita pelas 13 províncias que integravam a Confederação Argentina e que nomearam como presidente o governador de Entre Rios, Justo José de Urquiza, líder de uma coalizão contra Rosas.
} 
venção orgânica em assuntos sociais do Estado argentino em construção. Essa instituição nasceu sob a égide do processo de secularização da vida social e política dos Estados modernos. Um dos mentores da Sociedade de Beneficência, Bernardino Rivadavia, representou aquelas correntes de pensamento que propuseram a emancipação da moral da religião e reivindicavam o primado da razão sobre as verdades reveladas. Contudo, essa instituição conformou-se como um mix público-privado e perdurou, embora com mudanças, até o século XX. No momento da instituição da beneficência, a pobreza foi explicada por meio de dois argumentos: o azar (doença, morte ou acidente), ou a falta de moral ou ausência de virtude. A ação da beneficência foi uma iniciativa do poder público moralizante e não constitui uma resposta a uma demanda ou a uma exigência na qual se impunha uma visão da sociedade organizada com deveres e obrigações como corresponderia a um Estado de direito.

Segundo Boris Fausto e Fernando Devoto (2004) a situação do Brasil e da Argentina, em 1850, não era muito alentadora, em vários terrenos. Contudo, por meios diferentes, ambas as nações vinham consolidando certa unidade. No Brasil, havia o claro reconhecimento de um poder estatal; na Argentina, uma espécie de se habituar a um estado de coisas - a Confederação de fato, tutelada por Buenos Aires. A Argentina não contava de saída com nenhuma das vantagens do caso brasileiro. O Brasil possuía melhores condições de partida, como uma ordem políticoinstitucional mais estável. O poder imperial - tanto a dinastia imperial quanto a burocracia estatal -, fincou raízes na sociedade por meio de uma aliança de interesses, embora nem sempre harmônica, com os dois setores economicamente mais importantes: o dos grandes fazendeiros, sobretudo os cafeicultores, e dos grandes comerciantes.

A Carta Imperial de 1824 trouxe um primeiro intento de formalizar a proteção social por meio da proposta de garantia de socorros públicos. No entanto, as práticas assistenciais hegemônicas foram realizadas pela Igreja Católica, inspiradas naquelas que vinham sendo implementadas no Império, e, ancoradas no fundamento de caridade cristã. Com o advento da República, em 1889, é que ocorreram mudanças tendentes a institucionalizar medidas protetoras em direção de alguns setores do serviço público federal e a dar início a uma prática previdenciária sobre a qual se assentaram as bases de uma proteção formalizada.

Com a proclamação da República, o Brasil, assim como a Argentina, passou a adotar o mesmo sistema político: a República Federativa, inspirada no modelo norte-americano. As semelhanças do modelo institucional nos dois países evidenciam-se ao se comparar os textos das duas Constituições. Embora separadas, em sua promulgação, pelo espaço de pouco mais de 37 anos, ambas adotaram o sistema presidencialista, estabeleceram a divisão entre os poderes da República, fixaram as relações e respectivas competências da União (governo federal, no caso brasileiro) e dos estados (províncias, no caso argentino) etc. (FAUSTO e DEVOTO, 2004, p. 93-100).

A modernização política das nações coloniais passou a colocar na esfera estatal seu ponto principal de sustentação e a implementar um formato de política que compreendia as necessidades de seus habitantes por meio de procedimentos administrativos públicos como vinha sendo feito nos países que já tinham atingido 
certo grau de avanço na organização jurídico-estatal, mas no contexto de uma realidade social fundada em padrões ainda ligados à tradição.

No final do século XIX e primórdios do século XX, ocorreu um progressivo aperfeiçoamento dos sistemas previdenciários das nações europeias, cuja influência chegou aos demais continentes, principalmente à América Latina. A revolução industrial, iniciada na Europa no século XVIII e consolidada no século seguinte, deu impulso a mudanças de caráter econômico, social e político. Com a urbanização, os laços comunitários tradicionais foram desfeitos. Nesse processo, os problemas relativos à invalidez, morte prematura e velhice se tornaram relevantes. A esses problemas, somaram-se os acidentes de trabalho e o desemprego, que foram se definindo a partir de uma ótica previsível e regular e saindo do campo da responsabilidade individual para o da solidariedade. Vem daí a organização de uma forma de proteção assentada na técnica dos seguros, consolidada em 1883 na Alemanha. Inspirada nela, em 1898, surgiu a lei sobre acidentes de trabalho francesa. Entre 1902 e 1912, legislou-se sobre acidentes de trabalho na Argentina. No Brasil, isso aconteceu em 1919, com a primeira lei que responsabilizava as empresas por esses acidentes.

A ideia de igualdade liberal fundada na dupla indivíduo-cidadão foi contestada pela desigualdade social. Nesse cenário, acentuou-se a importância da criação e/ou fortalecimento de instituições estatais - por meio de políticas e organismos públicos - como elementos necessários para o tratamento da questão social e o estabelecimento de uma nova modernidade. As exposições internacionais que foram realizadas no final do século XIX promoveram a construção e a idealização das instituições dos Estados modernos. As cidades nas quais as exposições foram montadas - Londres, Paris, Chicago, entre outras - colocaram-se como o estágio mais avançado da civilização ocidental, mas que ainda conviviam com os problemas advindos da desigualdade social de uma grande parcela da população. Nesse sentido, as exposições serviam para mostrar também que tudo o que era familiar e seguro estava desaparecendo.

Nesse contexto, foi realizado, em Paris, no ano de 1889, o Congresso Internacional de Assistência Pública e Privada, em que se afirmou a necessidade de avançar em direção a uma atividade assistencial pública baseada em critérios racionais, e no desenvolvimento de um campo de saber para esta área que se assentou nos conhecimentos em saúde e em higiene pública. Para as instituiçõos privadas de assistência social, propôs-se que o Estado fosse o controlador de suas atividades (SPOSATI et al., 1985; SPOSATI, 1987; SPOSATI, 1994; MESTRINER, 1992; MESTRINER, 2001). Para esse evento, influíram notavelmente as ideias de Ataulpho de Paiva, acerca da organização da assistência social pública para o Brasil, embora não tenha sido concretizada até meados do século XX. Na Argentina, o Doutor Emilio Coni chegou a fundar - inspirado na experiência francesa -, a Assistência Pública da Capital Federal, em 1888. A França escolheu a via legal administrativa para legitimar as ações na área da assistência pública, uma resolução do Conselho de Estado, de 15 de fevereiro de 1909, define que a assistência pública é dada em virtude do direito da lei e não por uma decisão discricional da autoridade administrativa. 
\} A ASSISTÊNCIA SOCIAL NO UNIVERSO DA PROTEÇÃO SOCIAL - BRASIL, FRANÇA E ARGENTINA - CARRO, S. M. \}

Os efeitos do fim da Primeira Guerra Mundial manifestaram-se no pensamento como um projeto de transformação político-ideológica que implicou um debate sobre o papel do Estado e a introdução de uma nova legislação sobre o social. As correntes reformistas: liberal, católica e socialista, tinham posições diferenciadas sobre cada um desses pontos, mas as três coincidiram na necessidade de intervir na questão social e os seus intelectuais ocuparam papel importante nessa transformação. As ideias de estímulo à poupança, à previsão e à família como eixo da intervenção socioassistencial assentaram as bases de um discurso e de uma intervenção normativa na vida social mediada pelos aportes vindos do conhecimento científico vigente na época.

No Brasil, o movimento sanitarista organizou uma campanha nacional em defesa da saúde pública e a higiene, entre os anos de 1916 e 1920. Na Argentina, foi criado, em 1911, o Museu Social Argentino, inspirado no Museu Social de Paris, e, sob sua égide, foi inaugurada a Escola de Serviço Social, em 1930, ambas as instituições com inspiração higienista. Em 1933, foi realizada a Primeira Conferência Nacional de Assistência Social. Nela se avançou no papel do Estado como controlador das ações de assistência social e na modernização das instituições sociais.

A Igreja Católica assumiu uma postura crítica acerca das tendências do mundo moderno que resultou na criação de uma organização unitária e disciplinada apta para atuar na organização estatal e na sociedade. Desse espírito, nasceu a Ação Católica, em 1931, na Argentina e, alguns anos mais tarde, em 1935, no Brasil ${ }^{8}$. A primeira Escola de Serviço Social, no Brasil, surgiu em 1936, sob a inspiração da Igreja Católica.

As mudanças para a assistência social no período entreguerras ocorreram em direção de uma centralização da gestão governamental que a diferenciou, estrutural e institucionalmente, de outras formas de proteção ancoradas no mundo do trabalho. Um reordenamento institucional tendeu a dar especificidade ao social. $\mathrm{Na}$ França houve, nesse período, a extensão da assistência social pública a todas as comunas. Nos casos particulares da Argentina e do Brasil, foram institucionalizados os subsídios e o cadastro de entidades ligadas à assistência social e a outras formas socioassistenciais, como a caridade e a filantropia. Em 1932, foi criado, na Argentina, o Fundo de Assistência Social e, em 1937, instituído o Registro de Entidades de Assistência Social (ALAYON, 1980; ISUANI, 1985; GRASSI, 1989; TENTI FANFANI, 1989). Em 1938, foi criado, no Brasil, o Conselho Nacional de Serviço Social.

Destaca-se nesse período, a importância do Social Security Act, de 14 de agosto de 1935, editada nos Estados Unidos como uma das medidas do New Deal, do governo Roosevelt, em que se empregou pela primeira vez a expressão "seguridade social" ${ }^{9}$. Essa lei legitimou uma definição de seguridade social entendida como um conjunto de medidas que deveria agregar os seguros sociais e a assistência social, organizados e coordenados pelo poder público, visando atender ao desenvolvimento de toda a população. Além disso, estabeleceu um compromisso para

\footnotetext{
${ }^{8}$ Um conjunto de acontecimentos como a própria guerra, a Revolução Russa, a reivindicação operária dos anos de 1917 e 1921, nos dois países, e a crise de 1929, contornaram uma conjuntura de incertezas sobre as ideias liberais.

${ }^{9}$ Essa lei teve como finalidade mitigar os problemas sociais trazidos pela crise de 1929.
} 
com os Estados democráticos de promover um nível de vida minimamente digno para seus cidadãos.

Os relatórios da comissão formada pelo governo britânico e presidida por Sir William Beveridge, em 1942 e 1944, tiveram a influência das ideias de Roosevelt, no que tange ao postulado imperativo de erradicação das necessidades de toda a população, e pelo economista Keynes, na defesa da distribuição de renda. Nessa proposta, o Estado devia possibilitar a garantia da renda mínima, em caso de perda da capacidade para ganhá-la, assim como o acesso aos serviços estatais de saúde, educação e serviços sociais, pois por meio desse acesso se abriria a igualdade de oportunidades para todos os cidadãos. Essa igualdade de oportunidades significava a prática da cidadania.

A devastação econômica e social provocada pela Segunda Guerra Mundial impeliu a aceitação dos princípios de uma definição ampla de proteção social - baseada naqueles relatórios - por parte dos países europeus, que os obrigou a reformular as políticas voltadas ao social, ainda que tivessem saído vitoriosos do conflito armado. A França institucionalizou a seguridade social ideada e conduzida por Pierre Laroque, em 1945, e implantou, em 1946, uma nova Constituição Nacional.

A política de seguridade social previu que o sistema atingiria a todos os cidadãos, com o pleno emprego e as proteções associadas a ele. Paralelamente, a partir de 1953, consolidou-se uma ampla reforma jurídica da área da assistência social, que ampliou as diversas categorias beneficiárias e as características desses benefícios, que tinham sido legisladas em anos anteriores, para todos aqueles não inclusos no sistema nacional francês de seguridade social. O sistema de proteção social francês passou a incluir, além da ajuda monetária, o sistema de cuidados em domicílio para algumas categorias de beneficiários, na assistência social.

Embora existam numerosas críticas ao modelo de Estado Providência francês estruturado a partir dessa época, a assistência social não se constitui como uma medida isolada, pelo contrário, foi-se combinando ao interior do sistema de proteção social junto com a lógica previdenciária e a lógica da seguridade social, mas se consolidando como um campo com uma lógica própria, isto é, com uma legislação, uma organização e uma funcionalidade, com categorias e benefícios definidos, com uma nomenclatura própria ao interior do sistema de proteção.

Nos períodos pré e pós-Segunda Guerra Mundial, o posicionamento acerca da proteção social foi diferente, para o Brasil e para a Argentina.

Entre os anos 1930 e 1940, o Brasil, nos governos de Getúlio Vargas, desenvolveu uma parte da legislação trabalhista. O ordenamento constitucional de 1934 outorgou o marco jurídico necessário para que se assentasse parte dessas medidas. A Constituição de 1946 incorporou a noção de previdência social. Em 1942, foi criada, sob os cuidados da esposa do presidente, a primeira-dama, a Legião Brasileira de Assistência Social (LBA), inicialmente orientada para sustentar as necessidades daqueles que participaram do conflito armado, mas que evoluiu até se converter na maior instituição brasileira de assistência social, se considerada sua extensão aos Estados e as categorias atingidas.

Na Argentina, em 1944, foi criada a Direção-Geral de Assistência Social e, durante o primeiro governo do general Perón, foi criada a Fundação de Ajuda Social 
Eva María Duarte de Perón (1948). Na Constituição Nacional argentina de 1949, que rompeu com o esquema liberal da Constituição de 1853, destacaram-se os capítulos dedicados aos direitos do trabalho e dos idosos.

A Fundação Eva Perón e a Legião Brasileira de Assistência mostram, por um lado, o percurso socioassistencial das esposas dos presidentes, e, por outro, trazem as marcas de como o tratamento das expressões das questões sociais e assistenciais se relacionou ao feminino. Dizia Eva Perón, "me sinto responsável dos humildes como se fosse a mãe de todos" (GRASSI, 1989, p. 94). Revelou-se, nas duas instituições, um discurso que defendia a preponderância do sexo feminino, a natureza específica para a maternidade e o desempenho de atividades relacionadas ao bemestar das mulheres e das crianças, mas que, na prática, também foi acompanhado explícita ou implicitamente de um alto conteúdo político.

De fato, tanto Darcy Vargas como Eva Perón foram esposas de presidentes em exercício, e suas ações não poderiam estar fora de um cenário que impusesse ao mesmo tempo legitimidade aos atos dos homens pela via da ajuda social. Ainda quando os objetivos sob os quais ambas as instituições se fundaram fossem diferentes. Por um lado, a LBA associou-se ao esforço da guerra e da caridade, embora posteriormente evoluísse sob o nome de Legião Brasileira de Assistência. A Fundação Eva Perón surgiu sob um rechaço direto à beneficência, à caridade e à filantropia, e defendendo a ajuda social e ainda o direito à assistência social, nunca legislado. Talvez isso possa ser pensado pelas origens sociais diferentes das fundadoras. Evita provinha dos setores subalternos, enquanto que Dona Darcy era filha de fazendeiros. Evita teve um discurso altamente opositor à burguesia portenha, e as damas da beneficência foram um dos seus alvos. Dona Darcy invocou a classe média a compartilhar as atividades da LBA.

Ambas as entidades promoveram a ajuda social direta e se expandiram aos Estados e às províncias. As mulheres ocuparam um papel de destaque, nesse momento. Pelo lado da Fundação, Eva Perón se apoiou nas "células mínimas", militantes do Partido Peronista que não somente executavam a ajuda direta como levantavam os pedidos e as necessidades nas diferentes filiais. A LBA contava com as voluntárias femininas civis, que se transformaram em executoras das campanhas e estiveram presentes naqueles serviços que a instituição promovia.

A organização de ambas as instituições apresentou semelhanças e diferenças, que excedem as possibilidades de exposição deste trabalho, porém a Fundação Eva Perón existiu até dois anos depois da morte da sua fundadora, em 1954 - a infraestrutura da Fundação foi absorvida pelo Instituto Nacional de Ação Social, em 1955 - mas, apesar disso, sua presença permaneceu em boa parte na memória das gerações favorecidas por suas ações. A LBA perdurou no tempo, ultrapassou o governo de Vargas, e, embora modificada, introduziu - não sem acirradas críticas a incumbência da primeira-dama no campo assistencial, no Brasil, que subsistiu até finais do século XX, no nível federal, e se estendeu até hoje em todos os Estados e municípios brasileiros ${ }^{10}$.

\footnotetext{
${ }^{10}$ Esses dados surgem da pesquisa "Indicadores da gestão municipal da política de assistência social no Brasil: 2005/2006", realizada pelo Núcleo de Pesquisa em Seguridade e Assistência Social (NEPSAS) da PUC/SP.
} 
A configuração da assistência social no aparelho estatal da Argentina e do Brasil constitui um tema relevante não só pelas atividades da LBA e da Fundação quanto pelo próprio desenvolvimento do Serviço Social, como saber técnico, durante esse período. Ainda percebe-se uma dualidade entre esse saber e as atividades de ambas as instituições, porém a LBA, por haver permanecido vigente no tempo, conseguiu proceder a sua incorporação. Também coexistiram com formas estatais centralizadas com racionalidade administrativa voltada à assistência social; no caso brasileiro, com as atividades do Conselho Nacional de Serviço Social (CNSS), e, no caso argentino, com a Direção Nacional de Assistência Social, mas respondendo a lógicas diferentes. No caso da Fundação Eva Perón, houve certa restrição de algumas ações voltadas ao auxílio imediato, imprimindo um sentido de provisoriedade na prática que desenvolvera, mas, ao mesmo tempo, implantaram-se obras de infraestrutura de porte e magnitude - hospitais, escolas profissionais - que a ultra-passaram no tempo. A LBA chegou a possuir estrutura ampla de creches, lactários, educandários, centros comunitários, hospitais etc. e também providenciou assistência direta à população.

Em ambos os casos, persistiu o padrão da heterogeneidade e da fragmentação das práticas e não houve uma legislação que as enquadrasse e lhes desse legitimidade, como foi acontecendo no campo previdenciário. Ainda assim, a assistência social tem sido instrumento através do qual muitos indivíduos e grupos conseguiram satisfazer necessidades não contempladas até esse momento. Lazer, férias, serviços de infraestrutura, hospitais e escolas, no caso da Fundação Eva Perón. E rede de serviços sociais (creches, abrigo para idosos, atendimento a portadores de deficiências, hospitais) e serviços urbanos (abertura de ruas, construção de habitações para os sem renda, energia elétrica, perfuração de poços d'água), no caso da LBA.

A ampliação dos serviços sociais foi um dos fundamentos sobre o qual se modelaram as propostas de bem-estar durante a década de 1940. As avaliações ex post que ponderam sobre amadurecimento e desenvolvimento dos Estados de BemEstar nos três países revelam que eles foram se construindo sobre uma arquitetura estatal complexa e que nenhum deles responde a um modelo "puro".

No caso francês, defende-se a postura de um mix bismarckiano e beveridgiano e ainda destaca-se a herança da Revolução Francesa e do modelo republicano de desenvolvimento da assistência pública da Terceira República como diferenciador em face da classificação proposta por Esping Andersen. A partir de 1953, produziuse uma extensão do campo da assistência social que ampliou as categorias e os benefícios a partir da tipificação de carências e segmentos, porém também incorporouse o critério de comprovação de recursos para as prestações próprias da área (BORGETTO, 2004; PAQUY e BOURDELAIS, 2004; PALIER, 2003).

$\mathrm{Na}$ Argentina, alguns autores assinalam que ocorreu um momento de cobertura universal, entre 1950 e 1956, durante o governo do general Perón. Porém, considerada sua evolução, caracterizou-se por um modelo híbrido no qual primou a categoria do trabalhador sobre a de cidadão, de uma forma complexa baseada na superposição de direitos constitutivos como os de saúde e de educação e numa tensão entre a pretensão de universalidade de cobertura e uma prática particular orientada aos trabalhadores organizados e com cobertura por setores. Nessa 
perspectiva, a assistência social foi residual (GRASSI, HINTZE, NEUFELD, 1994; BARBEITO e LO VUOLO, 1995 e 1998).

No Brasil, prevaleceu um modelo de Bem-Estar ocupacional, em que o Estado transformou-se em regulador mediado pela legislação trabalhista, mas incorporando seletivamente setores da classe trabalhadora e com uma estrutura fragmentada, composta por multiplicidade de instituições baseadas no modelo bismarckiano de seguro individual ${ }^{11}$. A assistência social foi administrada hegemonicamente pela LBA e a assistência não ficou restrita aos organismos públicos de prestação direta de serviços. Por meio de subvenções ou convênios, foi repassada, às entidades sociais privadas, a execução de programas socioassistenciais e de serviços de infraestrutura social (creches, asilos, centros de formação de mão de obra, centros de reabilitação)(SPOSATI e CARVALHO, 1989).

Desde meados da década de 1980, impuseram-se mudanças nas formas de conceber a relação Estado e Sociedade, que provocaram alterações nos modelos forjados em torno da centralidade estatal, nos três países ligados à condução gerencial do aparelho de Estado. Os paradigmas sobre o Estado de Bem-Estar keynesiano foram substituídos por uma visão na qual primou o convencimento de que um retorno ao predomínio da lógica do mercado poderia resolver os problemas a respeito dos quais se queixavam a economia e a sociedade.

Assim, durante os anos 1980, a descentralização foi recomendada como estratégia para alcançar um modelo de Estado adequado ao processo de internacionalização das economias. Não obstante, a hegemonia dessa lógica como princípio da organização social e a diversidade de formas sobre as quais se vinha constituindo a sociedade e o Estado moderno, fizeram com que fosse processada de formas diversas e nem sempre resolvida pelo único recurso da instauração de mecanismos de mercado. Isso indica a existência de descentralizações que se exprimiram como um conjunto de tendências dentro da evolução de um sistema administrativo com características e conteúdos políticos intrínsecos.

Do ponto de vista político, nesse período, o Brasil e a Argentina saíram de ditaduras militares e editaram novas Constituições nacionais, em 1988 e 1994, respectivamente. A França manteve-se sob os preceitos da Quinta República, permanecendo vigentes os conteúdos constitucionais de 1958, porém sob mudanças nas diretrizes principais de recomposição da administração estatal, mas mantendo um Estado central forte, herança do processo de construção da nação.

$\mathrm{Na}$ França, os processos de descentralização administrativa do Estado foram interpretados como de desconcentração de decisões, pois o poder central permaneceu forte e definindo os lineamentos centrais das políticas prioritárias. A proteção social francesa tem como característica não se desfazer dos dispositivos instituídos, daí que, ao final de 2002, coexistiram o polo assistencial, como vinha sendo definido desde a Terceira República, e a Renda Mínima de Inserção, associados em

\footnotetext{
${ }^{11}$ Aldaíza Sposati denominou de um modelo de Bem-Estar Ocupacional, no qual são substituídas as relações de direitos constitucionalmente assegurados pelas de direito contratual; contudo, o campo da previdência social foi o dos "assegurados", e o campo da assistência social foi o dos "necessitados".
} 
uma lógica complementar e como resposta aos desafios do que se definiu como "nova pobreza", na qual se incluíam categorias e grupos aptos para o trabalho, mas sem possibilidade de inclusão nele.

No quadro das transformações da relação Estado-Sociedade que se deram na década de 1990, as organizações não governamentais - entidades da sociedade civil distintas do Estado e das instâncias governamentais - foram adquirindo um papel central para atuar em diferentes campos. Algumas delas orientaram-se à prestação de serviços diretos ou indiretos de promoção, capacitação, pesquisa, assistência técnica de grupos, comunidades e indivíduos excluídos do sistema formal de proteção social. A aide sociale francesa insere-se nelas, pois oferece mais que auxílio em dinheiro ou em espécie àqueles cujas necessidades não são atendidas por outros meios. Inclui serviços prestados aos doentes, idosos, alienados mentais e aos sem moradia.

Nesse contexto, e desde o ponto de vista da administração e organização da ação social, a lei francesa de 2002 trouxe à consideração e à revisão o quadro de instituições públicas e da sociedade civil prestadores de serviços de interesse público nos quais se incluíram aqueles ligados à aide sociale. Legislou sobre a racionalidade de recursos e de distribuição de funções. Reconheceu a necessidade de uma revisão dos princípios sobre os quais se assentaria a prestação dos serviços, de modo que cada estabelecimento deveria explicitar-se em relação à competência que lhe caberia em face das administrações departamentais. Assim como impôs a inclusão dos direitos dos usuários de estabelecimentos médicos e sociais como elementos fundamentais de seu funcionamento.

$\mathrm{Na}$ Argentina, a descentralização significou, do ponto de vista administrativo e no que tange às políticas sociais, a transferência de serviços nacionais às províncias, porém, em 1995, foi criada a Secretaria de Desenvolvimento Social, ligada à Presidência da República, como uma tentativa de integrar os programas e as áreas diversas da política social e superar a incerteza, por meio de uma função geral de orientação normativa dos programas de intervenção, enquanto que a execução e a operação passaram a corresponder aos níveis administrativos locais e provinciais. Nesse momento, no esquema administrativo de planejamento e execução de programas sociais, não apareciam claramente definidas as funções que compreenderiam os organismos nacionais em relação com as instâncias provinciais locais públicas e privadas, somado ao caráter descontínuo das intervenções. No interior das grandes categorias programáticas, desenvolveram-se atividades e serviços segmentados segundo a tipificação de carências, apresentado alterações e variações de acordo como o quadro conjuntural.

Em 2001, foi criado o Conselho Nacional de Coordenação de Políticas Sociais, cujo objetivo era coordenar e superar os obstáculos que a fragmentação institucional de programas e da administração provincial de políticas trouxeram ao funcionamento do sistema. A configuração da assistência social argentina foi se enquadrando nesse esquema de funcionamento.

A partir da crise argentina de 2001, exprimiram-se posicionamentos que colocaram na agenda pública o debate a respeito do princípio discricionário sobre o qual foi se estruturando a política social argentina. Uma leitura das Constituições 
provinciais vigentes, e das colocações de autores do campo do direito previdenciário argentino, revela a recorrência à noção de amparo, auxílio, ou ajuda às famílias e aos segmentos da sociedade, quando se trata de configurar a assistência social.

A noção de amparo significa proteção como abrigo ou resguardo, mas também indica impedimento a que ocorra proteção. A noção de proteção indica maior vigilância e tende a desenvolver ações para que alguma destruição não venha ocorrer (SPOSATI, 2007). Daí que o debate sobre a estrutura da política social argentina, além de postular os problemas de administração ou descentralização das políticas, impõe a necessidade de um desvelamento de condicionamentos e de aprofundamento dos princípios legais e constitucionais, como suporte analítico para pensar um projeto social que pondere direitos para todas as áreas das políticas sociais (KRMPOTIC e LUCUIX, 2001; ISUANI, 2006).

Os processos de descentralização administrativa, no Brasil, ganharam vários significados fundamentais para a assistência social no conjunto da proteção social. De fato, ela passou a ser reconhecida como direito e regulamentada na Lei Orgânica de Assistência Social (Loas), de 1993, que exprimiu diversas preocupações, além da descentralização. A Loas teve como intuito o estabelecimento de uma política baseada no direito à assistência social ancorada em mecanismos participativos de decisão. Esse esforço tendeu a promover uma reorganização de competências e atribuições entre as esferas de governo, bem como nos órgãos envolvidos pelas ações assistenciais provocando a decolagem de um processo amplo de descentralização política, administrativa e recentemente fiscal.

O processo de elaboração da Loas mobilizou universidades, instituições públicas, órgãos da categoria e meios políticos, na busca de um padrão democrático e social da assistência social. No debate sobre a política de assistência social brasileira, foi possível distinguir o papel dos intelectuais da área, no posicionamento de temas na agenda pública. O livro Carta Tema: a assistência social no Brasil: 19831990 denota quatro momentos no debate brasileiro sobre a assistência social, entre o final da década de 1970 e a década de 1980, que permitiram a desmontagem da noção não só como irracionalidade das primeiras-damas mas também como tática e estratégia no interior das políticas sociais brasileiras. Os três primeiros foram as reflexões sobre o processo de reconceituação do serviço social, a construção histórica que Marilda lamamoto e Raul de Carvalho realizam em seu livro Relações sociais e serviço social (1982), a retomada das políticas sociais no campo da previdência através da contribuição de Vicente Faleiros. A partir de 1983, com a pesquisa $A$ assistência na trajetória das políticas sociais brasileiras, do Programa de Estudos Pós-Graduados em Serviço Social da Pontifícia Universidade Católica de São Paulo, a partir da qual o tema da assistência social ganha eixos de análise: a organicidade da assistência social ao projeto societário brasileiro e organicidade da assistência social nas políticas sociais públicas (SPOSATI, 1989).

Ainda nos processos desenvolvidos a partir de 2004, foi definida a Política Nacional de Assistência Social, que introduziu a noção de segurança como um horizonte norteador para a assistência social. 


\section{Considerações Finais}

A pesquisa permitiu perceber que do ponto de vista do direito, a França acorre mais às necessidades, ainda, quando utiliza, desde a década de 1960, o critério de renda, pois os benefícios introduzem mecanismos de equidade que diferenciam para mais o valor de benefícios mínimos, operando maior justiça social. No Brasil, a assistência social permanece sob a seleção de renda, que prevalece sobre o tema da necessidade. Na Argentina, a assistência social traduz-se em uma proposta que envolve comprovação de renda associada à necessidade para alguns segmentos, mas prevalece, ainda assim, o princípio subsidiário.

A assistência social, nos três países, foi se erigindo sobre um discurso que envolve conteúdos constitucionais, legislação social, aparelhos institucionais, programas que articuladamente promoveram justificações e práticas que estigmatizaram a pobreza e o sistema que dela se ocuparia. $\mathrm{Na}$ assistência social, conviveram processos socioinstitucionais arcaicos e modernos, todavia quando ela é ancorada no diapasão da segurança social, sua compreensão fica facilitada como uma concepção de "possibilidade positiva", permitindo captar os avanços para o enfrentamento das desproteções e vicissitudes da vida humana. 


\section{Referências Bibliográficas}

ALAYON, Norberto. Hacia la historia del trabajo social en la Argentina. Lima: Celats, 1980. . Manual bibliográfico de trabajo social: América Latina y España. Buenos Aires: Consejo Latinoamericano de Ciencias Sociales, 1984. . Asistencia o Asistencialismo: ipobres controlados o erradicación de la pobreza?. Buenos Aires: Humanitas, 1989.

ALONSO, Guillermo V. Política y seguridad social en la Argentina de los '90. Buenos Aires: Miño y Dávila, 2000.

AZEVEDO MARQUES de SAES, Décio. "Direitos sociais e transição para o capitalismo: o caso da Primeira República Brasileira (1889-1930)". Estudos de Sociologia, Araraquara, vol. 11, n. 20. Araraquara: Unesp, 2006.

BARBEITO, Alberto; LO VUOLO, Rubén. La modernización excluyente: transformación económica y Estado de Bienestar en Argentina. Buenos Aires: Losada/Unicef, 1995. . La nueva oscuridad de la política social: del estado populista al neoconservador. Buenos Aires: Ciepp/Miño y Dávila Editores, 1998. BERTRANOU, Fabio M.; BONARI, Damián (Coords.). Protección social en Argentina: financiamiento, cobertura y desempeño, 1990-2003. Santiago/Chile: Oficina Internacional del Trabajo, 2005.

BORGETTO, Michel; LAFORE, Robert Droit de l'aide et de l'action sociales. Paris: Montchrestien, 2004.

CASTEL, Robert. La metamorfosis de la cuestión social: una crónica del salariado. Buenos Aires: Paidós, 1997.

¿La inseguridad social: qué es estar protegido? Buenos Aires: Manantial, 2004.

CHIRINOS, Bernabé L. La seguridad social y la Argentina. Buenos Aires: Ad-Hoc, 1991.

CONI, Emilio R. Higiene social: asistencia y previsión social, Buenos Aires caritativo y previsor. Buenos Aires: Imprenta de Emilio Spinelli, 1918.

DESTREMAU, Blandine; MESSU, Michel. "Le droit à I'assistance sociale à I'épreuve du local". In: Colloque International État et Regulation Sociales: comment penser la coherence de l'intervention publique. Paris, 2006.

DUPEROUX, Jean-Jacques. Droit de la sécurité sociale. Paris: Dalloz, 1980.

ESPING-ANDERSEN, Gosta. Los tres mundos del estado de bienestar. Valencia:

Ediciones Alfons el Magnànim-IVEI, 1993.

EWALD, François. L'État Providence. París: Grasset, 1986.

FALEIROS, Vicente de Paula. "A questão da assistência social". In: Serviço Social \& Sociedade, n. 30. São Paulo: Cortez, 1989.

FAUSTO, Boris; DEVOTO, Fernando. Brasil e Argentina: um ensaio de história comparada (1850-2002). São Paulo: Editora 34, 2004.

GRASSI, Estela. La mujer y la profesión de asistente social: el control de la vida cotidiana. Buenos Aires: Humanitas, 1989. 
. Políticas y problemas sociales en la sociedad neoliberal: la otra década infame (I). Buenos Aires: Espacio, 2003.

GRASSI, Estela; HINTZE, Susana; NEUFELD, María Rosa. Políticas sociales, crisis y ajuste estructural. Buenos Aires: Espacio, 1994.

HATZFELD, Henri. Du paupérisme à la sécurité sociale: essai sur les origines de la sécurité sociale en France:1850-1940. Paris: Armand Colin, 1971.

IAMAMOTO, Marilda Villela; CARVALHO, R. Relações sociais e serviço social no Brasil. São Paulo: Cortez-Celats, 1983.

ISUANI, Ernesto A.; LO VUOLO, Rubén M.; TENTI FANFANI, Emilio. El estado benefactor: un paradigma en crisis. Buenos Aires: Miño y Dávila, 1991.

ISUANI, Ernesto A. Los orígenes conflictivos de la seguridad social argentina.

Buenos Aires: Centro Editor de América Latina, 1985. . "Bismarck o Keynes: quién es el culpable. Notas sobre la Crisis de Acumulación". In: ISUANI, Ernesto A.; LO VUOLO, Rubén M.; TENTI FANFANI, Emilio. El estado benefactor: un paradigma en crisis. Buenos Aires: Miño y Dávila/CIEPP, 1991. de 2004.

. "Política social, derecho para todos". Buenos Aires: Clarín, 31 de agosto

. "Compensar o distribuir". Revista Mapas, n. 2. Buenos Aires: s/ed, novembro de 2006.

JOBERT, Bruno; MULLER, Pierre. L'État en action: politiques publiques et corporatismes. Paris: Presses Universitaires de France, 1987.

KRAWCZYK, Nora Rut; MORAES, Reginaldo C. Corrêa de. Estudos comparados, projeto histórico e análise de políticas públicas: entrevista com Hugo Zemelman. Revista Educação \& Sociedade, vol. 24, n. 82. Campinas: Unicamp, 2003. KRMPOTIC, Claudia Sandra; LUCUIX, María Beatriz. La reforma de la asistencia social en Argentina y Brasil: ciudadanía y marco-jurídico institucional en una perspectiva comparada. Buenos Aires: VI Congreso Internacional del CLAD sobre la Reforma del Estado y la Administración Pública, novembro de 2001. (Mimeo.) KRMPOTIC, Claudia Sandra. El derecho a la asistencia y la política de protección social en la construcción de un nuevo orden local-global". MENDICOA, Gloria E. (comp.). Hacia un proyecto de institucionalidad social en el Mercosur: opciones para el debate. Buenos Aires: Espacio Editorial, 2004. LOBATO, Mirta Zaida (dir.). Nueva Historia Argentina: El progreso, la modernización y sus límites (1880-1916). Barcelona: Sudamericana, 2000. MESTRINER, Maria Luiza. Assistência e seguridade social: oposições e aproximações. São Paulo: Pontifícia Universidade Católica, 1992. 264 p. (Dissertação, Mestrado em Serviço Social)

2001.

.O Estado entre a filantropia e a assistência social. São Paulo: Cortez,

PALIER, Bruno. Gouverner la sécurité social: les réformes du systéme français de protection sociale depuis 1945. Paris: PUF, 2003.

PANETTIERI, José. Las primeras leyes obreras. Buenos Aires: Centro Editor de América Latina, 1984. 
\} A ASSISTÊNCIA SOCIAL NO UNIVERSO DA PROTEÇÃO SOCIAL - BRASIL, FRANÇA E ARGENTINA - CARRO, S. M. \}

PAQUY, Lucie; BOURDELAIS, Patrice (Dirs.).Les systèmes européens de protection sociale : une mise en perspective. Direction de la recherche, des études, de l'évaluation et des statistiques, n. 6. Paris: s/ed, jan. 2004.

POLANYI, Karl. La gran transformación: los orígenes políticos y económicos de nuestro tiempo. México D.F.: Fondo de Cultura Económica, 1992.

ROMERO, José Luis; ROMERO, Luis Alberto (Dirs.). Buenos Aires: historia de cuatro siglos, tomo 2: Desde la ciudad burguesa (1880-1930) hasta la ciudad de masas. Buenos Aires: Grupo Editor Altamira, 2000.

ROZAS, Margarita. Las modificaciones de la intervención profesional en relación a la cuestión social en el contexto del Estado argentino: el caso del trabajo social. São Paulo: Pontifícia Universidade Católica, 2001. (Tese, Doutorado em Serviço Social).

SIMILI, Ivana Guilherme. A construção de uma personagem: a trajetória da primeira-dama Darcy Vargas (1930-1945). Seminário História, gênero e trajetória biográficas. Maringá: Universidade Estadual de Maringá, 2007.

SPOSATI, Aldaíza; BRANT DE CARVALHO, Maria do Carmo. A prática da assistência social: elementos para uma caracterização. Serviço Social \& Sociedade, ano VI, n. 19. São Paulo: Cortez, 1985.

. LBA: identidade e efetividade das ações no enfrentamento da pobreza brasileira. São Paulo: Educ, 1989.

. A assistência social brasileira: descentralização e municipalização. São Paulo: Educ, 1990.

SPOSATI, Aldaíza et al. Assistência na trajetória das políticas sociais brasileiras: uma questão em análise. São Paulo: Cortez, 1985.

SPOSATI, Aldaíza. Historia da pobreza assistida em São Paulo. São Paulo: Pontifícia Universidade Católica, 1987. 496p. (Tese, Doutorado em Serviço Social) . Vida urbana e gestão da pobreza. São Paulo: Cortez, 1988.

1988. . Carta tema: a assistência social no Brasil (1983-1990). São Paulo: Cortez,

.Modelo brasileiro de proteção social não contributiva: concepções

fundantes. São Paulo: PUC, 2007. (Mimeo.)

TENTI FANFANI, Emilio. Políticas de asistencia y promoción social en la Argentina Boletín de la Fundación Techint. Buenos Aires: s/ed,1987. Ceal, 1989. . Estado y pobreza: estrategias típicas de intervención/1. Buenos Aires:

THÉVENET, Amédée. L'aide sociale aujourd'hui: nouvelle étape pour la décentralisation. Issy-les Moulineaux cedex: ESF, 2004.

Recebido em 14 de abril de 2010.

Aceito para publicação em 25 de maio de 2010. 
